\title{
Does ketamine mimic aspects of schizophrenic speech?
}

Citation for published version (APA):

Covington, M. A., Riedel, W. J., Brown, C., He, C., Morris, E., Weinstein, S., Semple, J., \& Brown, J. (2007). Does ketamine mimic aspects of schizophrenic speech? Journal of Psychopharmacology, 21(3), 338-46. https://doi.org/10.1177/0269881107077729

Document status and date:

Published: 01/01/2007

DOI:

10.1177/0269881107077729

Document Version:

Publisher's PDF, also known as Version of record

Document license:

Taverne

Please check the document version of this publication:

- A submitted manuscript is the version of the article upon submission and before peer-review. There can be important differences between the submitted version and the official published version of record.

People interested in the research are advised to contact the author for the final version of the publication, or visit the DOI to the publisher's website.

- The final author version and the galley proof are versions of the publication after peer review.

- The final published version features the final layout of the paper including the volume, issue and page numbers.

Link to publication

\footnotetext{
General rights rights.

- You may freely distribute the URL identifying the publication in the public portal. please follow below link for the End User Agreement:

www.umlib.nl/taverne-license

Take down policy

If you believe that this document breaches copyright please contact us at:

repository@maastrichtuniversity.nl

providing details and we will investigate your claim.
}

Copyright and moral rights for the publications made accessible in the public portal are retained by the authors and/or other copyright owners and it is a condition of accessing publications that users recognise and abide by the legal requirements associated with these

- Users may download and print one copy of any publication from the public portal for the purpose of private study or research.

- You may not further distribute the material or use it for any profit-making activity or commercial gain

If the publication is distributed under the terms of Article $25 \mathrm{fa}$ of the Dutch Copyright Act, indicated by the "Taverne" license above, 


\section{Does ketamine mimic aspects of schizophrenic speech?}

Michael A. Covington CASPR, Artificial Intelligence Center, University of Georgia, Athens, Georgia, USA.

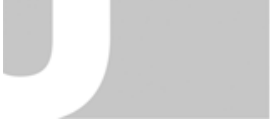

Journal of Psychopharmacology 21(3) (2007) 338-346 (C) 2007 British Association for Psychopharmacology ISSN 0269-8811 SAGE Publications Ltd, Los Angeles, London, New Delhi and Singapore $10.1177 / 0269881107077729$

Wim J. Riedel GlaxoSmithKline Research \& Development Ltd., Addenbrooke's Hospital, Cambridge, UK.

Cati Brown CASPR, Artificial Intelligence Center, University of Georgia, Athens, Georgia, USA.

Congzhou He CASPR, Artificial Intelligence Center, University of Georgia, Athens, Georgia, USA.

Eric Morris CASPR, Artificial Intelligence Center, University of Georgia, Athens, Georgia, USA.

Sara Weinstein Department of Psychiatry, University of British Columbia, Vancouver, BC, Canada.

James Semple GlaxoSmithKline Research \& Development Ltd., Addenbrooke's Hospital, Cambridge, UK.

John Brown GlaxoSmithKline Research \& Development Ltd., Addenbrooke's Hospital, Cambridge, UK.

\begin{abstract}
Speech disturbances are well-known symptoms contributing to the diagnosis of schizophrenia. Subanesthetic doses of the $\mathrm{N}$-methyl-D-aspartate (NMDA) antagonist ketamine have been reported to produce positive and negative symptoms and cognitive impairments consistent with those seen in schizophrenia. Insofar as this is true, it constitutes evidence that the NMDA system is involved in schizophrenia. It is therefore of interest to know whether ketamine produces speech disturbances like those of schizophrenia.

Quantitative computer-aided analysis of apparently normal speech can detect clinically relevant changes and differences that are not noticeable to the human observer.

Accordingly, in this study, speech samples were analysed for repetitiousness, idea density, and verb density using software developed by the authors. The samples came from two experiments, a within-subjects study of healthy volunteers given intravenous ketamine versus placebo, and a between-groups study of patients diagnosed with schizophrenia and comparable healthy controls.
\end{abstract}

Our primary hypothesis was that in both schizophrenia and ketamine, repetitiousness would increase, since perserverative speech is a well-known symptom of schizophrenia. Our secondary hypotheses were that in both schizophrenia and ketamine, idea density and verb density would decrease as indicators of cognitive impairment.

The primary hypothesis was confirmed in the schizophrenia experiment (between groups) and the ketamine experiment (within subjects).

The secondary hypotheses were disconfirmed except that in the ketamine experiment, verb density was significantly lowered. Reduced use of verbs apparently reflects a cognitive impairment of a different type than repetitiousness, and further investigation is needed to determine whether this impairment occurs in psychosis.

\section{Keywords}

ketamine, schizophrenia, N-methyl-D-aspartate (NMDA), speech, language, verbal behavior, perseveration, verbs, idea density

\section{Introduction}

Abnormal speech (defined as 'disorganized' speech and 'incoherence') is one of the core symptoms for diagnosing schizophrenia (Andreasen, 1979a, b; APA, 1994; Covington et al., 2005; McKenna and Oh, 2005). Administration of subanesthetic doses of the $N$-methyl-D-aspartate (NMDA) antagonist ketamine has been claimed to produce a condition mimicking psychotic symptoms, including disorganized speech, in healthy volunteers (Abi-Saab et al., 1998; Krystal et al., 2003). It is therefore of interest to know whether the speech disturbances in both conditions are comparable.

\section{Quantitative language measurements as disease markers}

Quantitative computer-aided analysis of apparently normal language can detect clinically relevant changes and differences that are not noticeable to the human observer. For example, Snowdon et al. (1996) and Kemper et al. (2001) were able to predict Alzheimer's disease from language samples taken more than 50 years before the onset of symptoms. Their subjects were a group of 678 elderly nuns who had written autobiographies when they joined their order, between age 20 and 25 . Text samples from these autobiographies 
were scored for grammatical complexity and idea density, ${ }^{1}$ and low scores on these measures, especially idea density, predicted Alzheimer's disease in late life. Crucially, all of the autobiographies were written in normal, comprehensible, standard English, and the differences were detected only quantitatively.

Snowdon et al. did their quantitative analysis by hand, but we use computers to make the analysis completely automatic and consistent. In the present study we compare the effects of ketamine and of schizophrenia by examining language production in speech samples.

\section{Biological theories of schizophrenia and their relation to language}

The neurobiological pathology associated with schizophrenia remains uncertain, but multiple lines of evidence suggest that schizophrenia is associated with 1) excessive stimulation of striatal dopamine (DA) D2 receptors, 2) deficient stimulation of prefrontal DA D1 receptors, and 3) alterations in prefrontal connectivity involving glutamate (GLU) transmission at NMDA receptors (Laruelle et al., 2003). Striatal dopaminergic hyperfunction is likely to be associated with agitated behaviors that probably also manifest in speech. Furthermore, it may also contribute to sensory gating deficits that result from deficits in early selection in information processing, hence leading to external and internal overstimulation and potentially hallucinations. In the frontal cortex, dopaminergic hypofunction is likely to be associated with impairment of working memory, executive function, planning, and coherent thinking. These deficits may also manifest as impairments in the more pragmatic and semantic functions of language.

Disruption of glutamatergic neurotransmission would predict that a glutamate antagonist (at the NMDA receptor) such as ketamine would induce certain schizophrenia-like symptoms. Others have described several of these cognitive and physiological symptoms after ketamine and have speculated about their association with schizophrenia symptoms (Adler et al., 1999; Salomé et al., 2000; Krystal et al., 2003).

\section{Language disturbances in schizophrenia}

Speech disturbances in schizophrenia are diverse. Linguists generally analyse language into five levels, phonology, morphology, syntax, semantics and pragmatics, and disturbances have been observed at all five levels (see Covington et al., 2005; McKenna and Oh, 2005 , for a full review). The most marked disturbances tend to be at the levels of semantics and pragmatics and reflect impaired executive function. The speaker fails to follow a discourse plan, returning needlessly to the same topic (perseveration) or drifting aimlessly while failing to convey the originally intended information.

One regularly mentioned characteristic of schizophrenic speech is that it is uninformative (McKenna and Oh, 2005: 23-25). We hypothesize that this impression reflects low idea density and results from difficulty following a discourse plan.

\footnotetext{
${ }^{1}$ For explanation of idea density, see under 'Assessments' below.
}

Repetition (perseveration) is another well-known characteristic of schizophrenic speech (Andreasen, 1979a; Covington et al., 2005; McKenna and Oh, 2005: 23-24) and has been studied quantitatively by Manschreck et al. (1985). This, too, can be understood as difficulty progressing toward a discourse goal or as dysfluency at a lower level, such as lexical retrieval or sentence construction.

\section{Hypotheses and approach}

In this study, we used software of our own design to measure repetitiousness (perseveration), idea density, and verb density (number of verbs per $N$ words).

Based on exploratory work with this and related data sets, our primary hypothesis was that in both schizophrenia and ketamine, repetitiousness would increase, since perserverative speech is a well-known symptom of schizophrenia. Our secondary hypotheses were that in both schizophrenia and ketamine, idea density and verb density would decrease as indicators of cognitive impairment.

The underlying question was whether schizophrenia is accurately replicated by low-dose ketamine. Additionally, this study enabled us to test the feasibility of detecting schizophreniform impairment through computerized quantitative speech measurements.

\section{Methods}

\section{Experiments}

Schizophrenia experiment There were initially 14 patients and 15 controls, of whom 11 patients and 12 controls yielded usable data.

Fourteen patients were originally recruited from the Vancouver Hospital's Schizophrenia Day Program as well as through the primary care physician. All patients had a diagnosis of schizophrenia according to DSM-IV criteria. Fifteen controls were recruited with advertisements posted around the University of British Columbia campus, and received either $\mathrm{C} \$ 20$ or an MRI film of their brain as compensation. Controls were screened for a history of psychiatric illness, and all subjects were screened for a history of head injury, neurological disorder and substance abuse. Since this dataset was originally gathered as part of an fMRI study, three controls and two patients were excluded from the original (and current) study for reasons related to MRI-specific parameters. One patient was excluded for being left-handed. These exclusions provided a final count of 12 controls ( 5 female, 7 male, mean \pm S.D. age $=32.6 \pm 12.4$ years) and 11 patients (5 female, 6 male, mean \pm S.D. age $=34.8 \pm 12.6$ years) whose speech samples are considered in our current study.

All of the 12 controls and 11 patients actually used in the study were right-handed (Edinburgh Handedness Inventory, Oldfield, 1971) native Canadian English speakers with no history of head injury or neurological disorder. In the patients, the diagnosis of schizophrenia was confirmed using the Signs and Symptoms of Psychotic Illness (SSPI) rating scale (Liddle et al., 2002a; mean \pm S.D. SSPI $=9.27 \pm 6.3$ ). Groups were matched for age, IQ as measured with the National Adult Reading Test (Nelson, 1982) and Quick Test (Ammons and Ammons, 1962), and parental 
socioeconomic status (Hollingshead Index, Hollingshead and Redlich, 1958). The mean \pm S.D. years of education was $15.1 \pm 2.5$ for the schizophrenics and $17.9 \pm 2.7$ for the comparison subjects. There were no significant differences between patients and controls in terms of age $(p=0.38)$ or years of education $(p=0.11)$.

The patients were stable outpatients with no recent changes to their medication. Of the 11 , three $(27 \%)$ were receiving typical and six $(55 \%)$ atypical antipsychotic medication; two (18\%) were receiving both. Additionally, five patients $(45 \%)$ were also taking antidepressants, all of which were serotonin reuptake inhibitors.

All participants provided informed written consent. Experimental procedures were approved by the University of British Columbia's Clinical Research Ethics Board, and use of the data was approved by the Human Subjects Office of the University of Georgia.

As part of this experiment (elsewhere reported by Weinstein et al., 2005), subjects were recorded describing pictures from the Thematic Apperception Test (TAT) (Murray, 1971) using the administration procedure outlined in Liddle et al. (2002b). For each subject, pictures 6GF, 7GF, 18BM, 13B, 9BM, 15, 12BG and 20 were used in that order; these range from easy to interpret visually to somewhat ambiguous. These recordings were transcribed by typists unaware of each subject's psychiatric status. The mean \pm S.D. length of the speech samples was $946 \pm 262$ words.

Ketamine experiment There were initially 12 subjects, all healthy, of whom nine yielded usable data.

Twelve healthy male volunteers, age (mean \pm SD) $29.7 \pm 6.5$, took part in an experiment conducted at the Addenbrooke's Centre for Clinical Investigation of GlaxoSmithKline Research and Development, Addenbrooke's Hospital, Cambridge, UK. All volunteers were provided with detailed information about the nature of the study before signed consent was collected. Prior to study commencement, subjects underwent a full medical examination and were screened according to standard criteria for healthy volunteer participation in pharmacological studies. These included age $21-45$ years, body mass index within the range $19-30 \mathrm{~kg} / \mathrm{m}^{2}$, no abnormalities on clinical examination, clinical chemistry or hematology, 12-lead electrocardiogram, Hepatitis B and C screen and urine drug screen. Exclusion criteria were any psychoactive medication or substance use or history of abuse, history or presence of gastro-intestinal, hepatic, renal or cardiovascular conditions, exposure to more than three new chemical entities within 12 months prior to the first dosing day, participation in another clinical trial with any drug within 84 days before the start of the study, participation in another clinical trial with a different new chemical entity within 112 days before the start of the study, having donated more than $1000 \mathrm{~mL}$ blood in the previous 12 months or $500 \mathrm{~mL}$ over the preceding 6 weeks, or hairstyle incompatible with the effective application of an electrode cap. Finally, to exclude subjects with personal or family history of psychiatric illness or evidence of psychiatric disturbance, all volunteers were administered the SCID-NP standardised semi-structured interview (First et al., 2002). The experiments were approved by the local Ethics Committee, and use of the data was approved by the Human Subjects Office of the University of Georgia.

A single-blind crossover design was employed. Each subject was tested with three different dosage regimens: placebo, the sub-anesthetic dose of ketamine under which data were gathered for this study, and a slightly higher dose of ketamine used to gather data for other purposes. The subjects were given the same tasks under all three conditions.

Conditions were spaced apart at least seven days. The sequence of doses was order-balanced across subjects according to Latin squares. Assignment of each subject number to one of the orders was random.

In each test, subjects received intravenous infusions of an induction dose of ketamine administered over the induction period followed by a constant dosage rate per hour during the maintenance period.

The ketamine dosage regimen used in this study consisted of a loading dose of $0.40 \mathrm{mg} / \mathrm{kg}$ spread over $10 \mathrm{~min}$ followed by maintenance at the rate of $0.21 \mathrm{mg} / \mathrm{kg} / \mathrm{h}$ for a total of $90 \mathrm{~min}$. Nine of the 12 subjects were successfully recorded under placebo and this regimen.

Thirty minutes into the infusion, a speech sample of about 10 min duration was recorded. Subjects were asked to describe pictures from the TAT (Murray, 1971). Each subject saw a different set of pictures on each study day. Specifically, pictures 1, 6BM, 17GF and 7BM were used for each subject's first session; 7GF, 5, 2 and 10 for the second; and $6 \mathrm{GF}, 18 \mathrm{GF}, 9 \mathrm{BM}$ and $9 \mathrm{GF}$ for the third. These pictures were selected from the TAT as a whole because they are relatively easy to interpret visually, though of course they are not completely free of the visual and emotional ambiguity which is the TAT is designed to exemplify.

Speech recordings were delivered to the experimenters as audio files and were transcribed by typists unaware of each subject's ketamine status. The mean \pm S.D. length of the speech samples was $256 \pm 107$ words.

\section{Assessments}

Repetitiousness (perseveration) Repetitiousness (perseveration) is an often-noted characteristic of schizophrenic speech (Andreasen, 1979a; Covington et al., 2005; McKenna and Oh, 2005: 23-24) and has been demonstrated quantitatively (Manschreck et al. 1985). We hypothesized that ketamine as well as schizophrenia would produce a measurable increase in repetitiousness.

We used a new technique for scoring repetitiousness which is incorporated into Natural Language Analysis Tools (NLAT), a proprietary software package developed by co-authors Covington and Morris for GlaxoSmithKline Plc.

NLAT analyses its text input into individual words and removes suffixes using the Porter stemming algorithm (Porter, 1980). It then checks whether each word is a recurrence of an earlier one.

Recurrrences are counted in a weighted fashion so that recurrences of recent words count for more than recurrences of more distant ones. The weighting is done with the sigmoid curve $g(x)$ shown in Fig. 1. The formula for the sigmoid curve has no deep theoretical significance, but it is quick to calculate. Finally, the total score is divided by the number of words to produce a repetition score for the text.

Idea density Snowdon et al. (1996) established the value of idea density as a neuropsychiatric measurement. Since schizophrenia is 


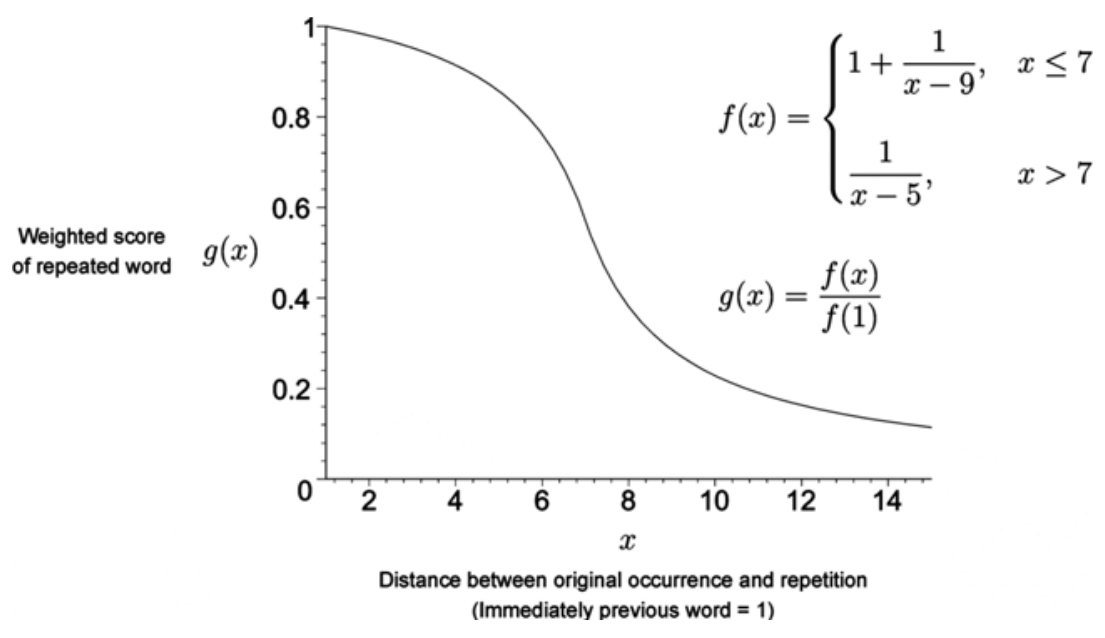

Figure 1 Sigmoid function for scoring repetitiousness.

known to involve wide-ranging cognitive impairment (Goldberg et al., 2003), we hypothesized that idea density would be reduced in schizophrenia and with ketamine.

Idea density is the number of propositions in a text divided by the number of words. Propositions are units of information. For example, The big dog barks in the garden contains three propositions: the dog is big, the dog barks, and it happens in the garden.

The term proposition comes from philosophical logic, in which a proposition is whatever can be true or false. In psychology, however, the criteria for identifying propositions have been shaped by empirical experiments, mainly on memory and text comprehension (Bransfor and Franks, 1971; Kintsch and Keenan, 1973; Ratcliff and McKoon, 1978; Kintsch and van Dijk, 1978; and especially Kintsch, 1974; 1988; Turner and Greene, 1978).

In English, the number of propositions in a text is almost identical to the total number of verbs (excluding all forms of do, have and be), adjectives, adverbs, prepositions, and subordinating conjunctions (but not nouns or coordinating conjunctions). Thus, idea density can be measured with part-of-speech tagging software. For this analysis, the texts were tagged with the current (2005) version of CLAWS (Garside, 1996) using its CL5 (BNC) tagset. The job of the tagger is to use both a built-in dictionary and rules of grammar to 'tag' each word as a noun, verb, adjective or other syntactic category.

We took the number of propositions (ideas) to be the number of CLAWS tags of types AJ0 (adjectives), AJC (comparative adjectives, e.g. better), AJS (superlative adjective), AV0 (adverb), AVP (adverbial particle), AVQ (wh-adverb, e.g. why, when), CJS (subordinating conjunction, e.g. although), PRF (the preposition of ), PRP (prepositions other than of), VM0 (modal verb), VVB (lexical base verb), VVD (past tense form of lexical verb), VVG (lexical verb + ing), VVI (infinitive of lexical verb), VVN (past participle form of lexical verb, e.g. taken), and VVZ ( $+s$ form of lexical verb, e.g. takes). The verbs $d o$, have and be were excluded, even though they sometimes express propositions, because in most cases they are auxiliary verbs, and distinguishing non-auxiliary occurrences of them would require further analysis.
Idea density was calculated as the total count of the aforementioned tags (the number of propositions) divided by the total number of words, which was obtained by counting all the tags other than punctuation marks.

Verb density Verb density is the number of verbs (lexical and modal) divided by the total number of words. Verbs are loci of syntactic and semantic complexity because they are the nexus of argument structure (subject, object, indirect object) (Jackendoff, 2002). Impairment in the use of verbs is well known in aphasia (Druks, 2002).

Since schizophrenia is known to involve simplification of syntax, probably reflecting simplification of semantics (Morice and McNicol, 1985, DeLisi, 2001), we hypothesized that idea density would be reduced in schizophrenia and with ketamine.

Note that verb density is a component of idea density; that is, verbs are one of several syntactic categories that are counted to determine idea density.

\section{Statistical Analyses}

All statistics were computed with SAS version 9 (SAS Institute, Cary, NC, USA) using PROC TTEST. The significance level threshold was set at $p=0.05$.

Between-groups two-tailed $t$-tests were carried out to test the difference between schizophrenic patients and healthy controls. Within-subject two-tailed paired $t$-tests were done to test for the effects of ketamine.

\section{Results}

Comparisons of the measured variables in both experiments are summarized in Fig. 2. Within-subject changes for the ketamine experiment are summarized in Fig. 3. 


\section{Between-Groups Differences}
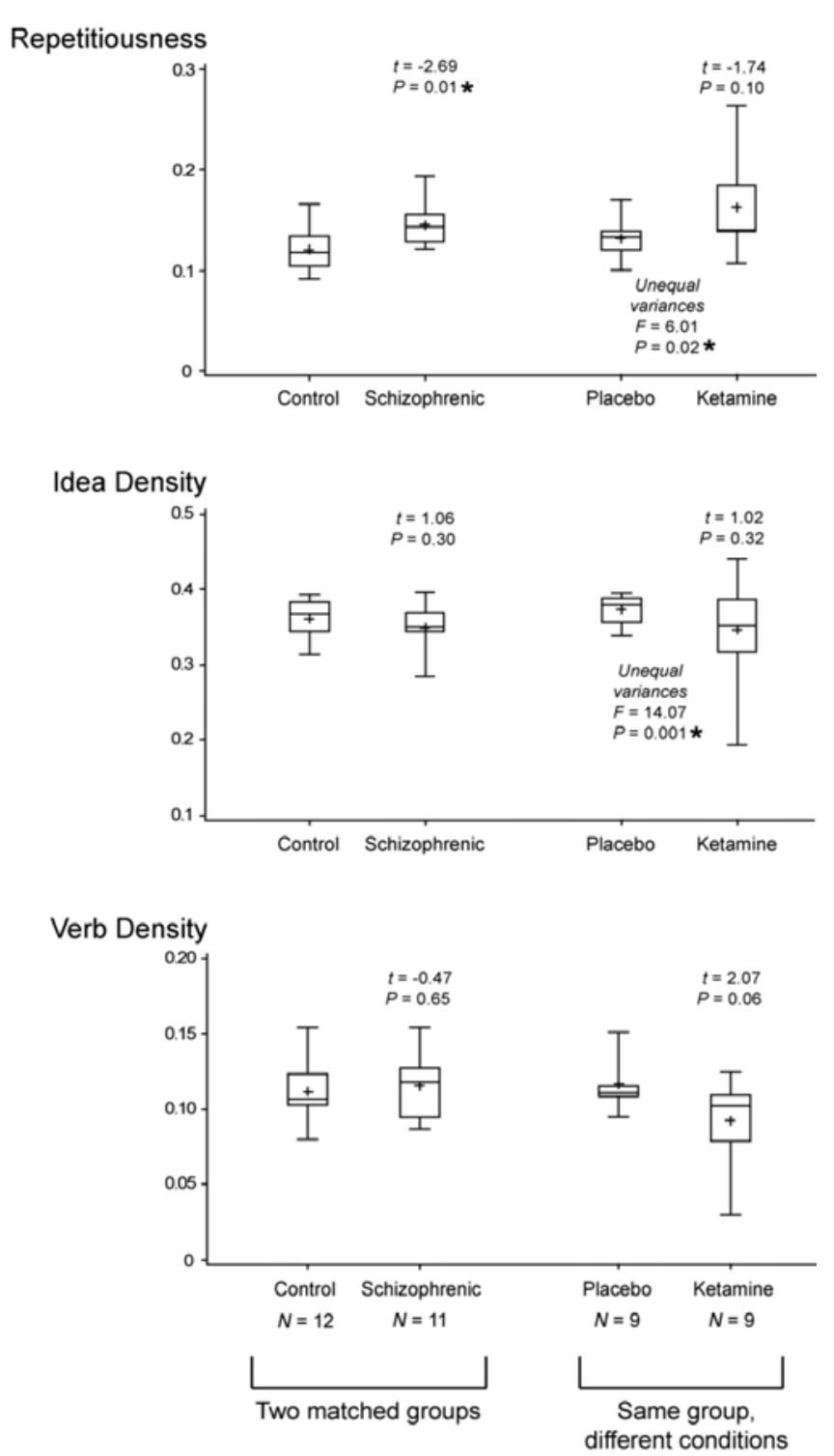

Figure 2 Comparison of measured speech characteristics between groups Box plots show minimum, quartiles, maximum, and mean $($ as +$)$. Values are indicated as mean \pm standard deviation.

\section{Schizophrenia}

Repetitiousness. The weighted repetition score in schizophrenic patients' speech, divided by total number of words, averaged 0.145 ( \pm 0.022 S.D.); for healthy controls, this value averaged 0.121 ( \pm 0.022 S.D.). Between-groups $t$-tests revealed that this difference was statistically significant $(t=-2.69, \mathrm{df}=21$, $p=0.01)$.
Idea density Schizophrenic patients' speech contained $0.349 \pm 0.030$ (mean \pm S.D.) propositions per word, whereas healthy controls' speech contained $0.362 \pm 0.026$. This difference is not considered meaningful and between-groups $t$-tests revealed no statistically significant difference $(t=1.06, \mathrm{df}=21$, $p=0.30)$.

Verb density The speech of schizophrenic patients and of healthy controls contained, respectively, $0.116 \pm 0.020$ and $0.112 \pm 0.022$ verbs per word. Between-groups $t$-tests revealed no statistically significant difference $(t=0.47, \mathrm{df}=21, p=0.64)$.

\section{Ketamine}

Repetitiousness The weighted repetition score, divided by total words, averaged $0.162( \pm 0.049 \mathrm{SD})$ in ketamine-influenced speech and $0.132( \pm 0.020 \mathrm{SD})$ in placebo speech. The mean \pm S.D. change in each subject, from placebo to ketamine, was $+0.031 \pm 0.038$. Within-subject paired t-tests revealed that this difference was significant $(t=2.40, \mathrm{df}=8, p=0.04)$.

Idea density Ketamine-influenced speech on average contained 0.346 ( \pm 0.076 S.D.) propositions per word, whereas placebo speech contained $0.373 \pm 0.020$ propositions per word. The means of the groups were not significantly different $(t=1.02$, $\mathrm{df}=16, p=0.33)$, but the standard deviation of the ketamine group was significantly higher $(F=14.07, p=0.001)$, showing that the effect of ketamine was appreciably different from subject to subject.

The mean \pm S.D. change in each subject, from placebo to ketamine, was $-0.027 \pm 0.063$. Within-subject paired $t$-tests showed that this change was not statistically significant $(t=-1.28, \mathrm{df}=8$, $p=0.24)$.

Verb density Ketamine-influenced speech on average contained 0.092 ( \pm 0.030 S.D.) verbs per word, whereas placebo speech on average contained $0.117 \pm 0.019$ verbs per word. The mean \pm S.D. change in each subject, from placebo to ketamine, was $-0.024 \pm 0.021$. Within-subject paired $t$-tests revealed that this

difference was statistically significant $(t=-2.61, \mathrm{df}=8$, $p=0.03)$.

\section{Discussion}

\section{Main results}

This is an initial study, with small-scale experiments, of entirely new techniques. As far as we know, this is the first demonstration of the use of computer speech analysis to detect and compare language abnormalities in schizophrenia and ketamine.

The results only partly fit our hypotheses, which were that both schizophrenia and ketamine would increase repetitiousness, reduce idea density, and reduce verb density. In fact, repetitiousness was significantly elevated in both schizophrenia and ketamine, but idea density was not significantly different, and only ketamine produced a significant drop in verb density. 


\section{Within-Subject Changes (Ketamine Experiment)}
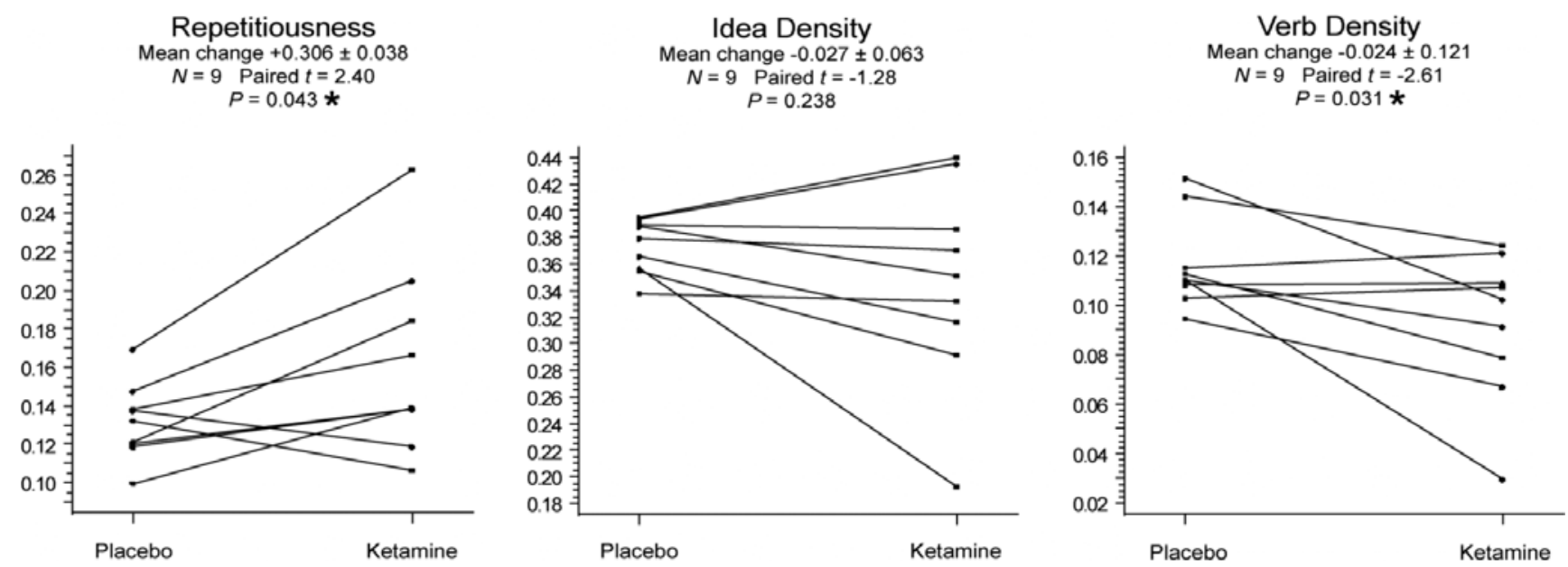

Figure 3 Ketamine experiment: within-subjects changes in measured speech characteristics.

\section{High variance of all measures with ketamine}

One generalization that is evident from Fig. 2, though not predicted by our hypotheses, is that the variance of all the measures is appreciably higher in the ketamine group than in any of the others. In two instances the difference is statistically significant: repetitiousness, ketamine versus placebo, $F=6.01, p=0.02$; idea density, ketamine versus placebo, $F=14.07, p=0.001$. In exactly those cases, the means are different but fail to be statistically significant because of the high variance of the ketamine group.

From this we conclude that the effects of ketamine are highly variable from subject to subject, and that this variability makes our hypotheses unexpectedly hard to test.

\section{Repetitiousness (perseveration)}

This is the only measurement that was statistically significant in both experiments (Figs 2 and 3). Both schizophrenia and ketamine produced significantly more repetitiousness. In this respect, ketamine reproduced a symptom of schizophrenia, although the effect was apparently larger (Fig. 2, upper right, and Fig. 3). With ketamine, the effect, even though apparently large, was significant only within subjects and not between groups because of the large variance of the ketamine group.

Adler et al. (1999) also found a larger increase in repetitiousness with ketamine than with schizophrenia. They obtained comparable scores on all Thought, Language, and Communication scale items except perseveration, which was appreciably higher with ketamine (mean 1.3 versus 0.6 , significant prima facie but not after their Bonferroni correction for multiple comparisons).

Perseveration is usually interpreted as executive impairment, but repetition over a relatively short interval, such as we measured, could also reflect impaired access to the lexicon (causing the speaker to try the same thing over and over) or difficulty assembling complete linguistic structures (somewhat like stammering). Regardless of its neural basis, it is apparently a characteristic that schizophrenia and ketamine have in common.

\section{Idea density and verb density}

Idea density was not significantly reduced either in schizophrenia or with ketamine. As Fig. 2 shows, the means were slightly lower than in the control groups, but the difference was not statistically significant. The variance of idea density was much higher with ketamine than in schizophrenia or in either control group.

From this we conclude that neither schizophrenia nor ketamine produces a drop in idea density like that observed in Alzheimer's disease. Verb density, a component of idea density, was significantly reduced with ketamine but not in schizophrenia (Fig. 2, bottom; Fig. 3, right).

Reduced use of verbs is manifested as a tendency to speak in noun phrases rather than sentences. Here are two samples of the same volunteer's speech, with and without ketamine (not describing the same picture, of course):

With ketamine, showing reduced use of verbs:

It looks like a scene from a port of something. There's uh a sunset. There's a river. There's a boat. Someone on a-on a bridge type - type of thing and a house.

Without ketamine, with normal use of verbs:

It's a farmyard scene. There's a a young farmer plowing a field with his horse. And a young girl. It looks like she's going to college or something with some books. And there's another woman. Sort of farmer type woman leaning against a tree. 
Recall that in each case the speaker is describing a picture, a task that can be performed either with whole sentences or with a list of noun phrases without verbs. Thus, some type of picture description is probably an ideal task for eliciting reduced versus normal use of verbs.

It is well established that verbs are harder to produce than nouns (in the sense that production is more easily impaired), both for healthy speakers in experimental situations (Szekely et al., 2005 and literature reviewed there) and in aphasic speakers, especially if the latter are sentence-production-impaired (Bak et al., 2001; Berndt et al., 2002; Druks, 2002). Verb production impairment has been attributed to executive impairment (Silveri et al., 2003), although a simpler explanation is that verbs simply require more cognitive or linguistic processing, since they normally require arguments (subject, object, etc.) whereas nouns do not.

Regardless of the neural basis of reduced use of verbs, it is an effect that distinguishes ketamine from schizophrenia. Classic studies of idea density (e.g. Snowdon et al., 1996) should be reexamined to determine whether reduced use of verbs was actually the phenomenon observed in those studies

\section{Strengths and weaknesses of this study}

Dosage regimen The dosages of ketamine in this experiment were in keeping with those in the literature reporting on subjective and objective effects of ketamine (Newcomer et al., 1999). The possibility remains that a different dose of ketamine would have produced a more accurate simulation of schizophrenia.

Magnitude of changes As percentages of baseline score, the changes that we report as significant were relatively large. Comparing schizophrenia to healthy controls, mean repetitiousness was up $20 \%$. Comparing ketamine to placebo, the mean intrasubject increase in repetitiousness was $23 \%$ of the mean placebo score, and the mean intra-subject decrease in verb density was $20.5 \%$ of the mean placebo score.

Although these numbers have not been calibrated to establish a norm, they are large enough to lead us to believe that the changes are clinically and neuropsychologically meaningful.

Multiple comparisons We tested three hypotheses on two sets of data, resulting in a grand total of six significance tests, ${ }^{2}$ three of which were significant.

Because the hypotheses are separate, we treat the significance tests separately (cf. Perneger, 1998). They are not multiple tests of a single null hypothesis.

Each hypothesis was indeed tested on two experiments, and arguably, two-way Bonferroni correction should be performed; it would cut the $0.05 p$-value threshold in half. However, in all cases we performed two-tailed $t$-tests even though the hypotheses were one-sided. Switching to one-tailed $t$-tests would also cut the $p$-values in half and leave our conclusions as they are.

${ }^{2}$ Fig. 2, left two columns, and Fig. 3. The right two columns of Fig. 2 are shown with significance values for comparison but were not used to draw conclusions.
Although the effect sizes were small, all of the significant outcomes were in the predicted direction, and hence it does not seem likely that null hypotheses were rejected while they were in fact true. It should be kept in mind that this is a preliminary study and the results should be interpreted as directional.

Method of speech elicitation using pictures The speech samples were elicited with pictures from the TAT, whose original purpose was to elicit emotional concerns rather than simple prose descriptions. Different pictures, designed to be relatively easy to describe, would presumably be more suitable for an experiment of this type. Other special-purpose paradigms may be useful; for example, lexical access can be probed very precisely with the picture-word interference paradigm (Miozzo and Caramazza, 2003).

Two other concerns are that the two experiments (schizophrenia and ketamine) used different sets of TAT pictures and elicited speech samples of considerably different length ( $946 \pm 262$ words for schizophrenia versus $256 \pm 107$ words for ketamine).

Note however that our measurements were designed to be independent of text length; all involve dividing by the total number of words, and unlike for example the widely used type-token ratio, none of our measurements involve quantities that inherently change with the size of the text. Moreover, Fig. 2 makes it obvious that the control groups for both experiments received very similar scores.

Another possible issue is visual processing, which is known to be impaired in schizophrenia (Butler et al., 2005). Repetition in speech and reduced use of verbs could result from, respectively, disorganized processing of the image and a perceptual bias in favor of things rather than actions, rather than from a disorder of speech per se. This question deserves further investigation. Even so, our conclusions about whether ketamine models schizophrenia are unaffected; the only issue is what domain(s) of cognition are involved.

Sample size, sensitivity and specificity The small sample size used does not allow us to conclude much in the cases where no significant difference was found. Further, the relatively small number of observations in the between-groups comparison for schizophrenia left us with much less statistical power than the within-subjects comparison for ketamine. A larger sample of schizophrenia patients vs. controls might have shown the same results as the ketamine experiment, but that remains to be demonstrated in subsequent work.

Further investigation of specificity is warranted. We found a difference between schizophrenia and ketamine, but we do not know if the schizophrenia results also apply to other disorders, such as depression or Alzheimer's disease, nor whether the ketamine results also apply to other sedating drugs. These questions can be investigated in further experiments.

What we can conclude is that our methods have high sensitivity. Even with the small sample size used, in both schizophrenia and ketamine, significant differences were found between 'normal' and 'abnormal' speech, interpretable and in line with our hypotheses. 


\section{Usefulness of computerized quantitative language analysis}

One obvious advantage of computerized measurement over clinical interviews is that the computer never has preconceptions as to how a patient should be diagnosed.

Another striking advantage, evident in our results, is that the computer detected significant changes in language samples that were not abnormal. To a casual observer (personal, nonsystematic but consistent impressions by authors $\mathrm{CB}, \mathrm{CH}$ and $\mathrm{MC}$, all linguists), all the speech in all transcribed samples appeared grammatically, semantically and pragmatically normal. There were no readily evident schizophreniform impairments of the types classified by Andreasen (1979a, b) and McKenna and Oh (2005). ${ }^{3}$ It is quite likely that these changes could not have been detected by a clinician at all unless the clinician was making quantitative measurements manually.

Figs 2 and 3 make it clear that, with our speech measures, comparisons within subjects or between closely matched groups are much more revealing than absolute scores or comparisons between different populations. We conclude that tests like these are more likely to be useful for assessing the progression of impairment, by measuring a patient against him/herself, than for initial diagnosis.

Fortunately, that is exactly where better tests are needed. Initial diagnosis of schizophrenia is usually based on symptoms, but it is then difficult to tell whether a patient is getting better or is merely learning to conceal the disease. Speech measurements provide an objective way to assess a changing impairment. The patient does not have to learn or be persuaded to perform an experimental task, since speech is part of daily life.

Of course, we do not rule out the possibility that tests like these, refined and normed against a much larger population, could eventually be useful for initial diagnosis of schizophrenia and related disorders. Our research should lead to tests that pick up psychotic tendencies 'below the surface' before manifestation or below the threshold of normal diagnostic sensitivity. One possibility is that a subsequent study designed to gather speech data longitudinally (in audio journal style, perhaps) from individuals at risk for schizophrenia could reveal more subtle patterns of language change (such as those we see here in the ketamine data) that could be used to more effectively target and treat prodromal cases.

An obvious drawback of computerized speech analysis is the need to transcribe a recording as text. Unfortunately, computer speech recognition technology presently on the horizon will not solve the problem; automatically recognizing the speech of a total stranger who may be speaking abnormally is not yet feasible. Nonetheless, it is reasonable to expect that speech-recognition technology suitable for this task will one day become available, or that

\footnotetext{
${ }^{3}$ The same casual but consistent observations of the audio recordings from the ketamine experiment by $\mathrm{CB}, \mathrm{CH}$ and $\mathrm{MC}$ indicated that speech affected by ketamine was sometimes noticeably slower, more halting, and less clearly articulated than the controls, but those differences did not show up in the transcripts that were analyzed by computer. Audio recordings of the schizophrenia samples were not available.
}

shortcuts will be found, such as detecting perseveration without positive identification of the words. In any case, our present results are of interest for neurochemical reasons even if no direct clinical application is immediately feasible.

\section{Overall conclusions}

Like schizophrenia, ketamine causes speech to become more repetitious, indicating impairment of lexical access and/or of discourse organization. The effect is measurable even when the speech is not perceptibly abnormal. To this extent, ketamine mimics the cognitive impairment of schizophrenia.

Ketamine also produces a marked reduction in use of verbs which was not observed in our sample of schizophrenia, but may have been a factor in the reduced idea density observed by Snowdon et al. (1996) in prodromal Alzheimer's disease. Reduced use of verbs apparently reflects a cognitive impairment of a completely different type than repetitiousness, and further investigation is needed to determine whether this impairment occurs in psychosis.

In any case, we have demonstrated that computational linguistic methods can reveal subtle changes in speech that are not evident to the 'naked ear' or even, in all probability, the trained speech clinician, and that these changes indicate differences in neuropsychological status.

\section{Acknowledgments}

This research was funded by a contract with GlaxoSmithKline Research \& Development Ltd. (Michael A. Covington, principal investigator). We thank Don Potter of the University of Georgia and at least two anonymous referees for helpful comments; Paul Rayson of the University of Lancaster for allowing us to use the CLAWS tagger via the World Wide Web; Joe McFall and Bess Fjordbak for assistance with the research at a late stage; and Dennis Perez for statistical advice.

\section{References}

Abi-Saab W, D’Souza D C, Moghaddam B, Krystal J H (1998) The NMDA antagonist model for schizophrenia: promises and pitfalls. Pharmacopsychiatry 31: 104-109

APA (1994) Diagnostic and Statistical Manual of Mental Disorders, Fourth Edition (DSM-IV). American Psychiatric Association, Washington, DC

Adler C M, Malhotra A K, Elman I, Goldberg T, Egan M, Pickar D, Breier A (1999) Comparison of Ketamine-Induced Thought Disorder in Healthy Volunteers and Thought Disorder in Schizophrenia. Am J Psychiatry 156: 1646-1649

Ammons, R B, Ammons C H (1962) The Quick Test (QT): Provisional manual. Psychol Rep 11: 111-161

Andreasen N C (1979a) Thought, language, and communication disorders: clinical assessment, definition of terms, and assessment of their reliability. Arch Gen Psychiatry 36: 1315-1321

Andreasen N C (1979b) Thought, language, and communication disorders: diagnostic significance. Arch Gen Psychiatry 36: 1325-1330

Bak T H, O’Donovan D G, Xuereb J H, Boniface S, Hodges J R (2001) Selective impairment of verb processing associated with pathological changes in Brodmann areas 44 and 45 in the motor neurone diseasedementia-aphasia syndrome. Brain 124: 103-120

Berndt R S, Burton M W, Haendiges A N, Mitchum C C (2002) Production of nouns and verbs in aphasia: effects of elicitation context. Aphasiology 16: 83-106 
Bransfor J D, Franks J J (1971) Abstraction of linguistic ideas. Cognit Psychol 2: 331-350

Butler P D, Zemon V, Schechter I, Saperstein A M, Hoptman M J, Lim K O, Revheim N, Silipo G, Javitt D C (2005) Early-stage visual processing and cortical amplification deficits in schizophrenia. Arch Gen Psychiatry 62: 495-504

Covington M A, He C, Brown C, Naci L, McClain J T, Fjordbak B S, Semple J, Brown J (2005) Schizophrenia and the structure of language: the linguist's view. Schizophr Res 77: 85-98

DeLisi L E (2001) Speech disorder in schizophrenia. Schiz Bull 27: 481-496

Druks J (2002). Verbs and nouns: A review of the literature. J Neuroling 15: 289-315

First M B, Spitzer R L, Gibbon M, Williams J B W (2002) Structured clinical interview for DSM-IV-TR Axis I disorders, research version, nonpatient edition (SCID-I/NP). Biometrics Research, New York State Psychiatric Institute, New York

Garside R (1996) The robust tagging of unrestricted text: the BNC experience. In Thomas J, Short M (eds.), Using corpora for language research: studies in honour of Geoffrey Leech, pp. 167-170. Longman, London

Goldberg T E, David A, Gold J M (2003) Neurocognitive deficits in schizophrenia. In Hirsch S R, Weinberger D R, eds., Schizophrenia, 2nd ed., pp. 168-184. Blackwell, Malden, Massachusetts

Hollingshead A B, Redlich, F C (1958) Social class and mental illness. Wiley, New York

Jackendoff R (2002) Foundations of language: brain, meaning, grammar, evolution. Oxford University Press, Oxford, pp.132-149

Kemper S, Thompson M, Marquis J (2001) Longitudinal change in language production: effects of aging and dementia on grammatical complexity and propositional content. Psychol Aging 16: 600-614

Kintsch W, Keenan J (1973) Reading rate and retention as a function of the number of propositions in the base structure of sentences. Cognit Psychol 5: 257-274

Kintsch W (1974) The representation of meaning in memory. Erlbaum, Hillsdale, NJ

Kintsch W, van Dijk T A (1978) Toward a model of text comprehension and production. Psychol Rev 85: 363-394

Kintsch W (1988) The role of knowledge in discourse comprehension: a construction-integration model. Psychol Rev 95: 163-182

Krystal J H, D'Souza D C, Mathalon D, Perry E, Belger A, Hoffman R (2003) NMDA receptor antagonist effects, cortical glutamatergic function, and schizophrenia: toward a paradigm shift in medication development. Psychopharmacology 169: 215-233

Laruelle M, Kegeles L S, Abi-Dargham A (2003) Glutamate, dopamine, and schizophrenia: from pathophysiology to treatment. Ann N Y Acad Sci 1003: $138-158$

Liddle P F, Ngan T C, Duffield G, Kho K, Warren A J (2002a) Signs and Symptoms of Psychotic Illness (SSPI): a rating scale. Br J Psychiatry 180: $45-50$

Liddle P F, Ngan E T C, Caissie S L, Anderson C M, Bates A T, Quested D J, White R, Weg R (2002b) Thought and Language Index: an instrument for assessing thought and language in schizophrenia. Br J Psychiatry 181: $326-330$

Manschreck T C, Maher B A, Hoover T M, Ames D (1985) Repetition in schizophrenic speech. Language and Speech 28: 255-268.

McKenna P J, Oh T M (2005) Schizophrenic speech. Cambridge University Press, Cambridge, UK

Miozzo M, Caramazza A (2003) When more is less: a counterintuitive effect of distractor frequency in the picture-word interference paradigm. J Exp Psychol Gen 132: 228-252

Morice R, McNicol D (1985) The comprehension and production of complex syntax in schizophrenia. Cortex 21: 567-580

Murray H A (1971) Thematic apperception test. Harvard University Press, Cambridge, MA

Nelson H E (1982) The national adult reading test (NART) manual. NFERNelson, Windsor, Berks, UK

Newcomer J W, Farber N B, Jevtovic-Todorovic V, Selke G, Melson A K, Hershey T, Craft S, Olney J W (1999) Ketamine-induced NMDA receptor hypofunction as a model of memory impairment and psychosis. Neuropsychopharmacology 20: 106-118

Oldfield R C (1971) The assessment and analysis of handedness: the Edinburgh inventory. Neuropsychologia 9: 97-113

Perneger T V (1998) What's wrong with Bonferroni adjustments. Br Med J 316: 1236-1238

Porter M F (1980) An algorithm for suffix stripping. Program 14(3): 130-137. Online at http://www.tartarus.org/ martin/PorterStemmer/ def.txt

Ratcliff R, McKoon G (1978) Priming in item recognition - evidence for propositional structure of sentences. J of Verbal Learning and Verbal Behavior 17: 403-417

Salomé F, Boyer P, Fayol M (2000) The effects of psychoactive drugs and neuroleptics on language in normal subjects and schizophrenic patients: a review. Eur Psychiatry 15: 461-469

Silveri M C, Salvigni B L, Cappa A, Della Vedova C, Puopolo M (2003) Impairment of verb processing in frontal variant-frontotemporal dementia: a dysexecutive symptom. Dement Geriatr Cogn Disord 16: 296-300

Snowdon D A, Kemper S J, Mortimer J A, Greiner L H, Wekstein D R, Markesbery W R (1996) Linguistic ability in early life and cognitive function and Alzheimer's disease in late life: findings from the Nun Study. JAMA 275: 528-532

Szekely A, D'Amico S, Devescovi A, Federmeier K, Herron D, Iyer G, Jacobsen T, Arévalo A L, Vargha A, Bates E (2005) Timed action and object naming. Cortex 41: 7-25

Turner A, Greene E (1978) The construction and use of a propositional text base. Technical report (reprinted 1988), Institute of Cognitive Science, University of Colorado

Weinstein S, Woodward I S, Werker J F, Ngan E T (2005) Functional mediation of the association between structural abnormality and symptom severity in schizophrenia (conference abstract). Schizophr Bull 31: $439-440$ 